\title{
LOS SERVICIOS DE CERCANÍAS EN MADRID Y BARCELONA. UNA VISIÓN HISTÓRICA
}

\author{
SUBURBAN SERVICES IN MADRID AND BARCELONA. \\ A HISTORICAL VIEW \\ Rafael Barquín Gil*1, Miguel Muñoz Rubio \\ ${ }^{1}$ Universidad Nacional de Educación a Distancia, Madrid, España \\ ${ }^{2}$ Fundación de los Ferrocarriles Españoles
}

RESUMEN: Este trabajo traza una breve historia comparada del transporte ferroviario de cercanías de Madrid y Barcelona, desde sus comienzos durante la dictadura de Franco hasta 2015. La justificación del estudio radica en que las dos ciudades absorben la inmensa mayor parte de esos servicios; pero también en que las diferencias en las inversiones realizadas han sido y son un argumento político relevante que cuestiona el papel de la Administración Central como gestor de las infraestructuras de transporte. Lo cierto es que Madrid y Barcelona son, desde la perspectiva del transporte periurbano, ciudades con problemas muy diferentes, que además partían de situaciones históricas no comparables. De ahí la necesidad de realizar una análisis histórico y geográfico que sobrepase las limitaciones impuestas por el empleo de herramientas económicas. La principal conclusión es que entre Madrid y Barcelona ha habido un proceso de convergencia en la dotación de servicios de transporte.

PALABRAS CLAVE: cercanías, ferrocarril, Barcelona, Madrid.

ABSTRACT: This paper draws a brief comparative history of suburban transport in Madrid and Barcelona, from its beginnings in the Franco's dictatorship to 2015. The justification of this study is that the two cities absorb the vast majority of those services; but also that the differences in the investments have been and are a relevant political argument that questions the role of the Central Administration as manager of transport infrastructures. The truth is that Madrid and Barcelona are, from the perspective of periurban transport, cities with very different problems, which also started from historical situations not comparable. Hence the need to make a historical and geographical analysis that exceeds the limitations of economic tools. The main conclusion of this paper is that between Madrid and Barcelona there has been a process of convergence in the provision of transport services.

KEYWORDS: suburban train, railway, Barcelona, Madrid.

* Correspondencia a: Rafael Barquín Gil. Departamento de Economía Aplicada e Historia Económica. Facultad de Ciencias Económicas y Empresariales-UNED. c/ Senda del Rey 11, Madrid 28040 - rbarquin@cee.uned.es - https://orcid.org/ 0000-0001-5093-2621

Cómo citar: Barquín Gil, Rafael; Muñoz Rubio, Miguel (2019). "Los servicios de cercanías en Madrid y Barcelona. Una visión histórica»; Historia Contemporánea, 59, 91-125. (https://doi.org/10.1387/hc.18765).

Recibido: 13 noviembre, 2017; aceptado: 16 abril, 2018.

ISSN 1130-2402 - eISSN 2340-0277 / (C) 2019 UPV/EHU 


\section{Introducción}

Como es sabido, en el transporte de viajeros, el ferrocarril fue concebido como un medio destinado a satisfacer únicamente la demanda de los recorridos de larga distancia. Sin embargo, las transformaciones que conocieron las ciudades hicieron que comenzara a configurar, a partir del último tercio del siglo XIX, un servicio específico para resolver la movilidad de las poblaciones asentadas en las nuevas localidades que fueron surgiendo en torno a ellas. Ya el perspicaz Eduardo Maristany destacó en 1905, en la memoria que elaboró tras el viaje de estudios que hizo a Estados Unidos, cómo los ferrocarriles norteamericanos contaban con unas tarifas propias para la banlieue de las grandes ciudades ${ }^{1}$.

Algunos historiadores sitúan en España el precedente más remoto de esta oferta en los denominados «trenes de recreo» que Norte puso en servicio entre Príncipe Pío y El Escorial en $1877^{2}$. Sin embargo, dicha consideración solo cabe atribuírsela con propiedad al servicio que MZA inauguró en 1902 en el apeadero de Paseo de Gracia y a los trenes que Norte implantó, durante la primera década del siglo XX, en Príncipe Pío-El Escorial-Segovia y que, no casualmente, denominó como «trenes de banlieue». A pesar de su todavía modesta entidad, estos trenes fueron capaces de lograr una cierta familiaridad entre los madrileños hasta el punto de que $A B C$ utilizaba sin necesidad de explicarlo el mencionado galicismo; que, en definitiva, había logrado convertirse en el significante para identificar al nuevo servicio ferroviario.

Sería Indalecio Prieto, ministro de Obras Públicas durante la Segunda República, el primero en utilizar la denominación castiza para designar esta especialidad ferroviaria. En efecto, en el decreto de 10 de noviembre de 1932, que constituyó una comisión para estudiar los enlaces ferroviarios de Madrid, aparecía el vocablo «cercanías»; y lo hacía, además, con su significado actual: una oferta ferroviaria específica destinada a satisfacer la demanda de movilidad entre las grandes ciudades y sus áreas metropolitanas, así como la que se producía dentro de ellas. Ideas que plasmó con su habitual vehemencia en el afamado discurso que dio Prieto desde los micrófonos de Unión Radio de Madrid para explicar dicho proyecto: «otro principio admitido es el de que la travesía subterránea de Madrid

1 Maristany i Gilbert, 1905. 
debe dedicarse principalmente al servicio de cercanías, explotándola también con el metro y admitiendo algunos trenes de largo recorrido en tránsito, como ensayo, que pueden ser los internacionales».

Desde entonces las cercanías no han dejado de desarrollarse hasta constituir en la actualidad un servicio insustituible para hacer posible la movilidad en las principales ciudades españolas. Servicio que es proporcionado, cabe añadir, por diferentes modalidades públicas - ferrocarriles convencionales de diferentes anchos de vía, metropolitanos, tranvías y autobuses - y privadas - automóvil - . En este artículo nos vamos a ocupar exclusivamente de la gestionada por Renfe en Madrid y Barcelona; haciéndolo en ambos casos mediante una marca comercial denominada Cercanías o, en catalán, Rodalies, aunque en Barcelona también lo hacen los Ferrocarrils de la Generalitat de Catalunya (FGC).

Además de en estas dos conurbaciones, Renfe ofrece servicios de transporte de cercanías en Valencia, Bilbao, Málaga, San Sebastián, Sevilla, Asturias, Alicante/Murcia, Cádiz, Santander y Zaragoza. Pero Barcelona y Madrid son, con gran diferencia, las más importantes; su demanda medida por los viajeros transportados asciende al $83 \%$ del total nacional ${ }^{3}$. Además de por su importancia económica, la comparación entre los servicios públicos de las dos grandes ciudades de España, y especialmente los de transporte, se justifica porque forma parte del discurso político habitual de la España democrática, e incluso de la anterior.

Este ejercicio necesariamente ha de ser un análisis histórico. Cualquier evaluación sobre el acierto o error de las inversiones realizadas en las infraestructuras de transporte ferroviario, muy caras dada su naturaleza, solo cobra sentido si es acometida en el largo plazo, que es precisamente el ámbito de la Historia. El propósito de los autores de este trabajo es arrojar un poco de luz sobre este polémico asunto.

\section{Madrid}

\subsection{Contexto geográfico y poblacional}

Si nada se entiende sobre el papel desempeñado por Madrid en la Historia de España sin tener en cuenta su posición geográfica, tampoco

3 OFE, 2012 pp. 101-111. 
es posible comprender la historia de este transporte sin dicho condicionante. Madrid se levanta alrededor del curso medio del río Manzanares, en una comarca mal definida que, sin conformar un territorio realmente llano, tampoco presenta accidentes geográficos de importancia. La superficie que ocupa el término municipal de Madrid es relativamente grande, $606 \mathrm{~km}^{2}$, lo que en gran parte se debe a la existencia de parques y otros espacios naturales protegidos o no urbanizados. Esto explica que su actual densidad de población, $5.300 \mathrm{hab} / \mathrm{km}^{2}$, no sea mayor que la de otras ciudades españolas más pequeñas. De todos modos, incluso eliminadas esas áreas la densidad poblacional no parece excesiva. De hecho, la mayor de toda el área metropolitana de Madrid corresponde a Coslada, un municipio colindante, con $7.400 \mathrm{hab} / \mathrm{km}^{2}$.

Desde la segunda mitad del siglo xx la provincia de Madrid ha conocido una auténtica revolución demográfica. Entre 1950 y 2011 su población se multiplicó por 3,3, al pasar de 1,9 a 6,4 millones de habitantes. La clave de esta dinámica reside en la conformación de su área metropolitana, que entre esos dos años pasó de 200.000 a 3,1 millones de habitantes, mientras la capital hacía lo propio desde 1,6 a 3,2 millones ${ }^{4}$. El hecho de que la población del área metropolitana se multiplicara por 16,1 mientras que la de la capital solo se duplicara, significó, lógicamente, que la primera aportase el $63,6 \%$ de la ganancia, y que pasara de representar el 9,8\% del total provincial en 1950 al 47,5\% en 2011. En un primer momento, entre 1950 y 1970 , el crecimiento se concentró en la ciudad de Madrid, que absorbió el 83,2\% del mismo. Lo contrario sucedió entre

${ }^{4}$ En este trabajo se define «área metropolitana» o «urbana» a partir del concepto de conurbación desarrollado por el proyecto AUDES (Ruiz González, 2011). Existen otros criterios de delimitación. Tanto en el ámbito político como en el académico a menudo se han empleado los estrictamente administrativos como, por ejemplo, Corporación Metropolitana, Mancomunidad de Municipios, o NUTs (Nomenclature des Unités territoriales). También han sido usuales los criterios demográficos basados en la densidad poblacional. Para nuestros fines, creemos preferible seguir un criterio que ponga el acento en la actividad económica y la interacción de sus agentes, especialmente el movimiento de commuters. Bajo esta orientación se han formalizado conceptos como Áreas Urbanas Funcionales (FUR), Larger Urban Zones (LUZ) o Dynamic Metropolitan Areas (DMA). En general, las conurbaciones definidas de este modo suelen ser bastante más grandes que las que obedecen a criterios administrativos o demográficos, lo que también sucede con las AUs de Madrid y Barcelona del proyecto AUDES, que incluso son ligeramente mayores que sus respectivas DMA o FUR (Boix, Rafael y Paolo Veneri, 2009). La conurbación de Madrid estaría formada por 94 entidades pertenecientes a las áreas urbanas de Madrid y Guadalajara, así como las localidades de Illescas, Ciempozuelos, Aranjuez y Azuqueca. 
1970 y 2011, cuando el área metropolitana fue la que protagonizó el crecimiento al absorber el $82 \%$ del total. De hecho, entre 1981 y 2001, Madrid capital incluso perdió 0,3 millones de habitantes, que recuperó durante la siguiente década.

En definitiva, a lo largo del último medio siglo se ha conformado un nuevo espacio vertebrado en torno a una ciudad que duplicó su población. A su alrededor, en 2011 había nueve ciudades con una población superior a 100.000 habitantes — por orden de tamaño, Móstoles, Alcalá de Henares, Fuenlabrada, Leganés, Getafe, Alcorcón, Torrejón de Ardoz, Parla y Alcobendas - , que sumaban casi millón y medio de personas. En 1950 el conjunto de esas nueve ciudades no superaba los 50.000 habitantes. La más pequeña, Alcorcón, ni siquiera llegaba a 1.000. Por tanto, el crecimiento de esa área metropolitana se hizo sobre un territorio poco poblado y casi completamente agrario.

No obstante, ese territorio tenía una importante peculiaridad. Al ser Madrid el centro de la red ferroviaria española, las localidades de sus alrededores se convirtieron, sin proponérselo, en las etapas finales de las grandes líneas ferroviarias. Así, de las nueve ciudades citadas, en 1870 todas menos Alcorcón, Móstoles y Alcobendas tenían estación de tren. Y antes de acabar el siglo XIX, las dos primeras también estaban conectadas gracias al ferrocarril de Madrid a Almorox. Únicamente Alcobendas permaneció sin ferrocarril... ; hasta el año 2001! Y es que el hecho de que Madrid fuera el centro del sistema radial español no garantizaba una conexión regular de los pueblos de su provincia con la capital. Y tampoco el que esa conexión fuera buena. Ese ferrocarril de Almorox terminaría desapareciendo porque no daba un servicio satisfactorio, siendo sustituido en la década de 1970, en su tramo con más tráfico, por el Madrid-Móstoles.

\subsection{El origen moderno de las cercanías en Madrid}

El Horario-Guía de 1945 editado por Renfe recogía ya varias ofertas de cercanías. Por un lado, entre Madrid-El Escorial-Cercedilla circulaban trenes ómnibus - automotores eléctricos - entre las 9.25 y las 20.50 los días laborables, a los cuales había que añadir un tren directo más entre Madrid y Villalba y otros dos que realizaban el trayecto Madrid-El Escorial-Ávila. Durante los días festivos las primeras relaciones se incrementaban en una más y se ofertaban otras dos relaciones entre Madrid y Torrelodones. 
Y, por otro, entre Madrid y Aranjuez se habían establecido, entre las 8.10 y las 23.30, once relaciones prestadas por trenes ómnibus, correos y expresos, de las cuales solo dos circulaban algunos de estos días laborales; y entre Madrid y Toledo se contaban cinco relaciones (tres por Aranjuez y dos por Villaseca).

A pesar de que esta oferta anterior estaba identificando una nueva realidad que podía ser resuelta por el ferrocarril convencional, la cual Renfe no dejó de atender en la medida de sus mermadas posibilidades ${ }^{5}$, el Plan de Transportes de Madrid aprobado en $1956^{6}$, que fue redactado a partir de un estudio elaborado previamente por la Comisión Interministerial de Transporte ${ }^{7}$, lo ignoró completamente. Porque, en efecto, tras justificar en el preámbulo que su redacción se debía a la necesidad de que el Estado interviniese dada la falta de iniciativa privada, el plan circunscribía su actuación a la obligación de garantizar una oferta de transporte que hiciera posible la movilidad de las recientes zonas urbanizadas de la ciudad; razón por la cual depositaba dicha función exclusivamente sobre la EMT y el Metro.

El hecho de que el crecimiento de la provincia de Madrid se concentrase hasta 1970 en la capital constituye una primera circunstancia que ayuda a explicar que ni siquiera se contemplara la posibilidad de que el ferrocarril convencional jugara un papel como oferente del transporte de viajeros en la misma. Pero más difícil resulta razonar que se hiciera lo mismo en el caso de la movilidad entre Madrid y en sus áreas metropolitanas; y, más aún, que Renfe quedara excluida de la Comisión Coordinadora de Transportes de Madrid que la ley creó para tal fin.

Otra circunstancia que se debe tener en cuenta es que las cercanías fueran concebidas por Renfe como un servicio destinado a aquella parte de la clase media que encontró en la sierra madrileña un lugar idóneo para vivir o levantar una segunda residencia. De esta forma se pervirtió una de las principales aspiraciones de los «enlaces ferroviarios» de Indalecio

${ }^{5}$ Una monografía imprescindible para las cercanías de Madrid es Cayón, Cuéllar y Polo, 2003.

${ }^{6}$ Fue probado por la Ley de 12 de mayo de 1956 (BOE, 134, 13 de mayo de 1956, pp. 3.074-3.075.

7 Dicha comisión fue creada, a su vez, en 1954 y formada por los ministerios de Gobernación, Obras Públicas, Industria, Trabajo y Hacienda, así como por el ayuntamiento de la ciudad, el Metro y la EMT. 
Prieto: convertir la sierra en un barrio más de la ciudad para mejorar las condiciones de vida de las clases populares ${ }^{8}$.

\section{Cuadro 1}

Relaciones del tráfico de cercanías de Madrid en 1965

\begin{tabular}{|c|c|c|c|c|c|c|c|c|c|}
\hline \multirow{3}{*}{ Direcciones } & \multirow{3}{*}{$\begin{array}{c}\text { Viajeros } \\
\text { diarios }\end{array}$} & \multicolumn{4}{|c|}{ Salidas } & \multicolumn{4}{|c|}{ Llegadas } \\
\hline & & \multicolumn{2}{|c|}{ Invierno } & \multicolumn{2}{|c|}{ Verano } & \multicolumn{2}{|c|}{ Invierno } & \multicolumn{2}{|c|}{ Verano } \\
\hline & & diario & domingo & diario & domingo & diario & domingo & diario & domingo \\
\hline Villalba & 4.660 & 14 & 16 & 28 & 32 & 19 & 22 & 30 & 35 \\
\hline Guadalajara & 3.060 & 12 & 12 & 12 & 12 & 11 & 12 & 11 & 12 \\
\hline Aranjuez & 2.540 & 10 & 8 & 10 & 9 & 9 & 9 & 9 & 9 \\
\hline Ciudad Real & 1.500 & 8 & 9 & 8 & 9 & 8 & 9 & 8 & 9 \\
\hline Villaluenga & 540 & 3 & 3 & 3 & 3 & 3 & 3 & 3 & 4 \\
\hline Total & 12.300 & 47 & 48 & 61 & 65 & 50 & 55 & 61 & 69 \\
\hline
\end{tabular}

Fuente: Sofrerail,1967: 59.

Pero, además, como acertadamente sostuvo en 1967 la consultora francesa Sofrerail en el estudio que realizó para Renfe sobre el tráfico de cercanías en Madrid ${ }^{9}$, todos esos servicios no podían ser calificados como tales. Baste decir que algunos de ellos cubrían distancias de hasta $200 \mathrm{~km}$, cuando en Roma se situaban en los $58 \mathrm{~km}$, o en las otras grandes ciudades europeas se desenvolvían en un rango de entre 12 y $18 \mathrm{~km}^{10}$. La consultora gala, obligada, probablemente, por las limitaciones estadísticas, circunscribió su análisis a relaciones cuyas longitudes fueran inferiores a los $150 \mathrm{~km}^{11}$, que sumaban $669 \mathrm{~km}$ de línea (417 de ellos electrificados). De su cómputo concluía que dichos servicios desplazaban en 1965 a

8 Casas Torres y González Yanci, 1977; García Pérez, 2013; del Río, 1958, pp. 10-19 y 207; y Velarde Fuertes, 1983.

9 Sofrerail, 1967.

10 Sofrerail, 1967, p. 57.

11 Las relaciones eran: Atocha-Sigüenza (140 km); Príncipe Pío-Ávila (121 km); Príncipe Pío-Segovia $(101 \mathrm{~km})$; Delicias-Villaluenga $(50 \mathrm{~km})$; Delicias-Toledo $(91 \mathrm{~km}$ por Aranjuez y $77 \mathrm{~km}$ por Villaseca); y Atocha-Alcázar de San Juan (149 km); en Sofrerail, 1967. 
4,5 millones de viajeros; es decir, una media diaria de 12.300, que representaban el 40,8\% del total (30.150 viajeros) registrado en las tres estaciones de Madrid ${ }^{12}$.

Con las obvias limitaciones metodológicas, hay que señalar que en esta modesta demanda resultaban tan importantes los movimientos debidos a razones de ocio como los causados por motivos laborales o de estudio, habida cuenta de que eran similares el número de relaciones ofertadas los días laborales y los domingos durante el invierno; como, asimismo, eran superiores los primeros durante la etapa estival. La prioridad de garantizar la movilidad con la sierra seguía siendo lo que marcaba dicha oferta, ya que esas relaciones absorbían el 37,9\% de la demanda total (desde la estación de Villalba), y el promedio de pasajeros computados durante el verano llegaba a duplicar el de invierno. Acertadamente, se llamaba la atención sobre que, aun dándose una mayor concentración de trenes ofrecidos entre las siete y las ocho de la mañana, a diferencia «des trafics habituel de "banlieue" d'autres grandes capitales» europeas, en Madrid durante el resto del día se mantenía una oferta homogénea.

Las acertadas y oportunas observaciones de Sofrerail fueron echadas en saco roto y, por consiguiente, la situación se fue haciendo más grave en la misma medida en que se fue optando por el transporte por carretera, hecho que alcanzó su clímax cuando se diseñaron las políticas de las redes arteriales ${ }^{13}$. En 1971 el Ministerio de Obras Públicas aprobó el Plan de Cercanías de Madrid, cuya misma denominación llamaba a confusión pues solo pretendía mejorar los accesos por carretera a cinco enclaves naturales ubicados en las proximidades de la ciudad con el objeto de mejorar la calidad de vida de una parte de su población ${ }^{14}$. Aunque por entonces la preocupación de Renfe seguía girando en torno a cómo resolver los enlaces ferroviarios de la ciudad, todo lo más que se puede decir de ella es que ya comenzaba a entrever las posibilidades que tenían las cercanías para mejorar la oferta del transporte urbano de la ciudad.

Si las primeras encuestas de movilidad viarias - 1963 y $1964-$ comenzaban a demostrar la existencia de relevantes problemas de conges-

12 Sofrerail, 1967, pp. 31-32 y 57 y ss.

13 Figueroa, 1958 pp. 4-22.

14 Plan de Cercanías de Madrid de 1971, 1971 pp. 17-30. No puede calificarse más que como hilarante que entre los problemas que pretendía resolver estuviera la angustia, que siendo «un factor muy característico de la civilización actual [...] en las urbes alcanza su nivel máximo». 
tión ${ }^{15}$, el estudio realizado por COPLACO ${ }^{16}$ en 1971 confirmaba que, efectivamente, el transporte privado por carretera se había ido consolidando, de forma que los vehículos $/ \mathrm{km}$ recorrido en las carreteras provinciales se habían multiplicado, entre 1960 y 1969, por 3,9. En lo referente al ferrocarril, y teniendo en cuenta sus limitaciones estadísticas, este último estudio cifraba el tráfico de cercanías en 1970 en 3,2 millones de viajeros, frente a los 3,8 que asignaba al tráfico de largo recorrido ${ }^{17}$; guarismo que no podía ser calificado más que como ridículo si se comparaba con los 1.000 millones de viajeros movilizados por Metro, EMT y los Periféricos. Con razón, naturalmente, Cayetano Roca, partiendo de la encuesta domiciliaria de origen-destino realizada por COPLACO en $1974^{18}$, consideraba la participación de las cercanías de Renfe en la demanda del área metropolitana de Madrid como casi despreciable porque, además de que sus «frecuencias [y sus] horarios [no] eran adecuados para ofrecer un servicio suburbano» ${ }^{19}$, según sus datos, de los 4,5 millones de viajeros diarios que en este año se movían en el área metropolitana de Madrid el 22,1\% eran aportados por el automóvil privado y el 0,3\% (15.000 viajeros diarios) por ellas.

Tres años más tarde, Renfe e INECO realizaron un estudio más completo $^{20}$ en el que se cifraba la longitud de las siete líneas de Cercanías madrileñas en 404,7 km, por donde se movían diariamente 570 circulaciones y se ofrecían 494.720 plazas, de las que el 37,6\% eran sentadas ${ }^{21}$. Este documento, sumamente valioso para conocer con cierto rigor este servicio, incluía, además, una primera matriz origen-destino de un día laborable de marzo, la cual señalaba que los 76.377 viajeros diarios se concentraban en las líneas Aluche-Móstoles (el 56,9\%) y Madrid-Guadalajara (25,8\%). Dado que en la primera de ellas no se pudo confeccionar la matriz, tan solo cabe señalar que sus estaciones terminales acaparaban el 79,9\% de los registros totales. En la segunda, la matriz identificaba a los flujos MadridAlcalá de Henares y Madrid-Torrejón de Ardoz con un 12,6\% y 6\% del tráfico total, respectivamente; guarismos que señalan la preponderancia del tráfico consignado entre las estaciones de dicho corredor. Ahora bien, si

\footnotetext{
15 Aldama, 1964 pp. 14-22 y 1965 pp. 6-9; y María Briñis, 1967 pp. 24-27.

16 COPLACO, 1971.

17 COPLACO, tomo XI.

18 Roca, 1976 pp. 121-134.

19 Roca, 1976 pp. 130.

${ }^{20}$ Renfe e INECO, 1977.

21 Renfe e INECO, 1977 pp. 88, 93 y 163-167.
} 
exceptuamos la línea Aluche-Móstoles, solo el 32\% del tráfico tenía origen y destino en Madrid, lo que viene a demostrar que las cercanías en 1977 servían para garantizar la movilidad entre la capital y las otras localidades, pero, sobre todo, para hacer lo propio entre las localidades de cada corredor. Otro estudio posterior de la misma consultora vino a añadir que la mayoría de los viajeros que utilizaban las cercanías eran estudiantes $(25,1 \%)$, amas de casa y jubilados $(22,1 \%)$ y obreros industriales $(15,4 \%)^{22}$.

\subsection{La consolidación de las cercanías}

Aunque la crisis energética de 1973 incidió notablemente sobre un esquema que, en resumidas cuentas, apostaba por el transporte por carretera y negaba a las cercanías siquiera un papel que desempeñar, la reacción de las diferentes Administraciones Públicas fue tardía. Sería a partir de la siguiente década cuando concurriesen varias circunstancias que acabaron provocando una inflexión en la historia de las cercanías de Madrid. Solo entonces los gestores decidieron incorporar esta oferta en el transporte urbano con un papel protagonista. De manera sintética, cabe destacar, primero, la aprobación en 1982, por parte del Ayuntamiento de Madrid, de la Comisión de Planeamiento y Coordinación del Área Metropolitana y del Ministerio de Transportes, del I Plan Ferroviario para el Área Metropolitana de Madrid (I Plan de Cercanías 1980-1991) ${ }^{23}$, donde claramente la oferta de Renfe poseía ya la misma entidad que las otras modalidades. En segundo lugar, la Ley 5/1985, de 16 de mayo, que creó el Consorcio Regional de Transportes Públicos Regulares de Madrid (CRTM) con el objeto de coordinar, bajo una dirección centralizada, a las distintas modalidades concurrentes ${ }^{24}$. En tercer lugar, en 1987 el CRTM estableció el abono de transporte. En cuarto lugar, Renfe creó en 1988 la Dirección Autónoma de Cercanías con el objeto de prestar un servicio específico de estas características, que, un año después, pasaría a constituirse como una de las unidades de negocio en las que se vertebró la empresa. Y, finalmente, la aprobación del Plan de Transporte de Cercanías 1990-1993 de

22 INECO, 1978.

23 Según Esteras González, 1991 pp. 5-38, este plan fue resultado del Plan Especial de Infraestructura de Transporte de la Provincia de Madrid, aprobado por COPLACO en 1975, y del documento de Renfe «El Transporte de Cercanías (1978)».

${ }^{24}$ El CRTM nacía como una empresa pública y organismo autónomo de la Comunidad Autónoma de Madrid que asumía las competencias sobre el transporte público regular. 
Renfe, que conllevaba una altísima inversión selectiva para impulsar un segmento de transporte ferroviario asentado sobre 15 núcleos urbanos con una población de 1,6 millones de habitantes, si bien la mitad de esta inversión quedaba asignada a Madrid.

Este último aspecto merece ser destacado. En los 20 años trascurridos entre 1965 y 1985 se abrieron al tráfico en los alrededores de Madrid un total de $65 \mathrm{~km}$ de vías férreas, de modo que en ese último año la red de cercanías sumaba $241 \mathrm{~km}$. Desde 1986 y hasta 1993 se añadieron $37 \mathrm{~km}$. Desde entonces y hasta 2006 otros $62 \mathrm{~km}$. Y, finalmente, hasta 2013, se sumaron otros $51 \mathrm{~km}$. Así pues, ha habido una clara aceleración en la construcción de infraestructuras de transporte; en cada uno de esos cuatro períodos se han construido 3,3, 5,3, 4,7 y 10,2 km/año. La actual red de cercanías de Madrid cuenta con $391 \mathrm{~km}$. En todo caso, conviene tener en cuenta que, más allá de la longitud, se han realizado obras vitales para las comunicaciones internas de Madrid, como el túnel de conexión de cercanías entre las estaciones de Atocha y Chamartín, o el Pasillo Verde entre Principio Pío y Delicias ${ }^{25}$.

Como se observa en el gráfico 1, la evolución del transporte público en Madrid ratifica la decisiva importancia de estos cambios. Una primera etapa se caracterizó por una notable regresión del tráfico total. Entre 1974 y 1986, los viajes realizados en las diferentes modalidades de transporte ferroviario - en los que se incluyen los de cercanías - pasaron de 1.183 a 830 millones, una caída de casi el 30\%. Sin embargo, la producción de cercanías aumentó considerablemente. De los 12.300 viajeros diarios estimados por Sofrerail en 1965, estos servicios de transporte pasaron a 76.000 en 1978 y a 204.000 en los días laborables en $1985^{26}$. Todo esto permitió llevar su peso relativo en 1986 hasta el 7,2\%, cuando la EMT retenía el 47,4\% y Metro un 35,4\%. La oferta viene a ratificar este comportamiento de la demanda ya que, según Renfe ${ }^{27}$, en 1983 su servicio de cercanías de Madrid ofrecía 688 trenes los días de diario, 577 los sábados y 504 los festivos, lo que se traducían en una oferta 39.187 plazas en hora punta y en 53,3 millones de viajeros transportados durante todo el año ${ }^{28}$.

${ }^{25}$ González Yanci, 2012 pp. 483-506; Lerma Rueda, 2001 pp. 6-7

26 Esteras González, 1991 pp. 17.

27 Renfe, Jefaturas de Cercanías de 1. a y 2. Zonas (1984), Resultados de explotación de las cercanías de Madrid. Año 1983.

${ }_{28}$ Se habían pasado, a su vez, de las 15 relaciones de 1960 a 265 en 1984; en Gloria Fernández-Mayoralas Fernández, El Transporte de viajeros por ferrocarril en la Comunidad de Madrid, op. cit., p. 467. 


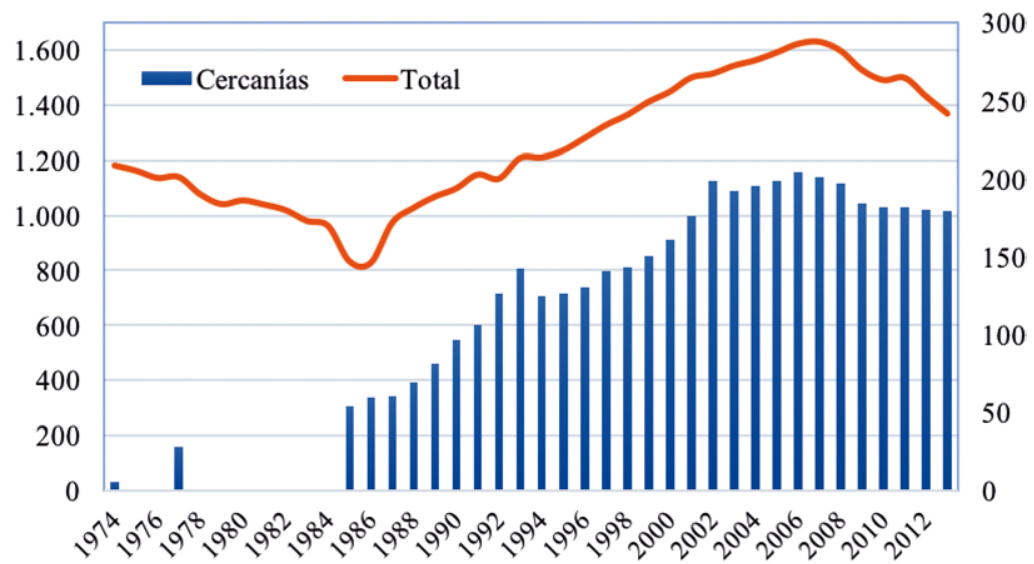

\section{Gráfico 1}

Evolución de la demanda del transporte público y de cercanías en Madrid, 1974-2013 (millones de viajes)

Fuente: Entre 1975-1985, CRTM, 1992, p. 89; entre 1986-2013, CRTM, 2013, p. 66 y

Renfe; entre 1974-1977 elaboración propia a partir de Renfe e INECO, 1977.

Desde 1987 hubo una franca recuperación en el conjunto del transporte ferroviario, etapa que finaliza en 2007, cuando ese tráfico alcanza su valor histórico máximo de 1.630,6 millones de viajes, es decir, en esos 20 años la producción se duplicó. Los servicios de cercanías también incrementaron su demanda, pero en una cuantía mayor que el resto de los servicios de transporte ferroviario. Entre 1986 y 1993 se alcanzó un crecimiento medio interanual del 20,5\%; y entre 1995 y 2006 del 12,3\%, menor al anterior pero aún muy elevado ${ }^{29}$.

El ejercicio de 2007 también marca el inicio de una última etapa, que llega hasta 2013, ahora de notable regresión puesto que durante ella se produjo una pérdida del $16 \%$ del tráfico total alcanzado en el primer año ${ }^{30}$;

${ }^{29}$ En 1994 Renfe modificó su sistema de cálculo de los viajes realizados, razón por la cual no se puede valorar el dato de este año, cifrado en 124,8 millones.

${ }^{30}$ Dicho comportamiento hace verosímil que se mantuviese tendencia del tráfico público a perder cuota de mercado en favor del transporte privado puesto que ya había pasado del 46\% en 1988 al 40,8\% en 1996; en Gutiérrez y García Palomares, 2005 pp. 339. También, de los mismos autores, 2007 pp. 81-82. 
cuya causa debe buscarse en la crisis económica que entonces comienza. Igualmente, la demanda de cercanías entre 2007 y 2013, experimentó una notable regresión con una media negativa del $6,7 \%$; con todo, también inferior al de los otros servicios.

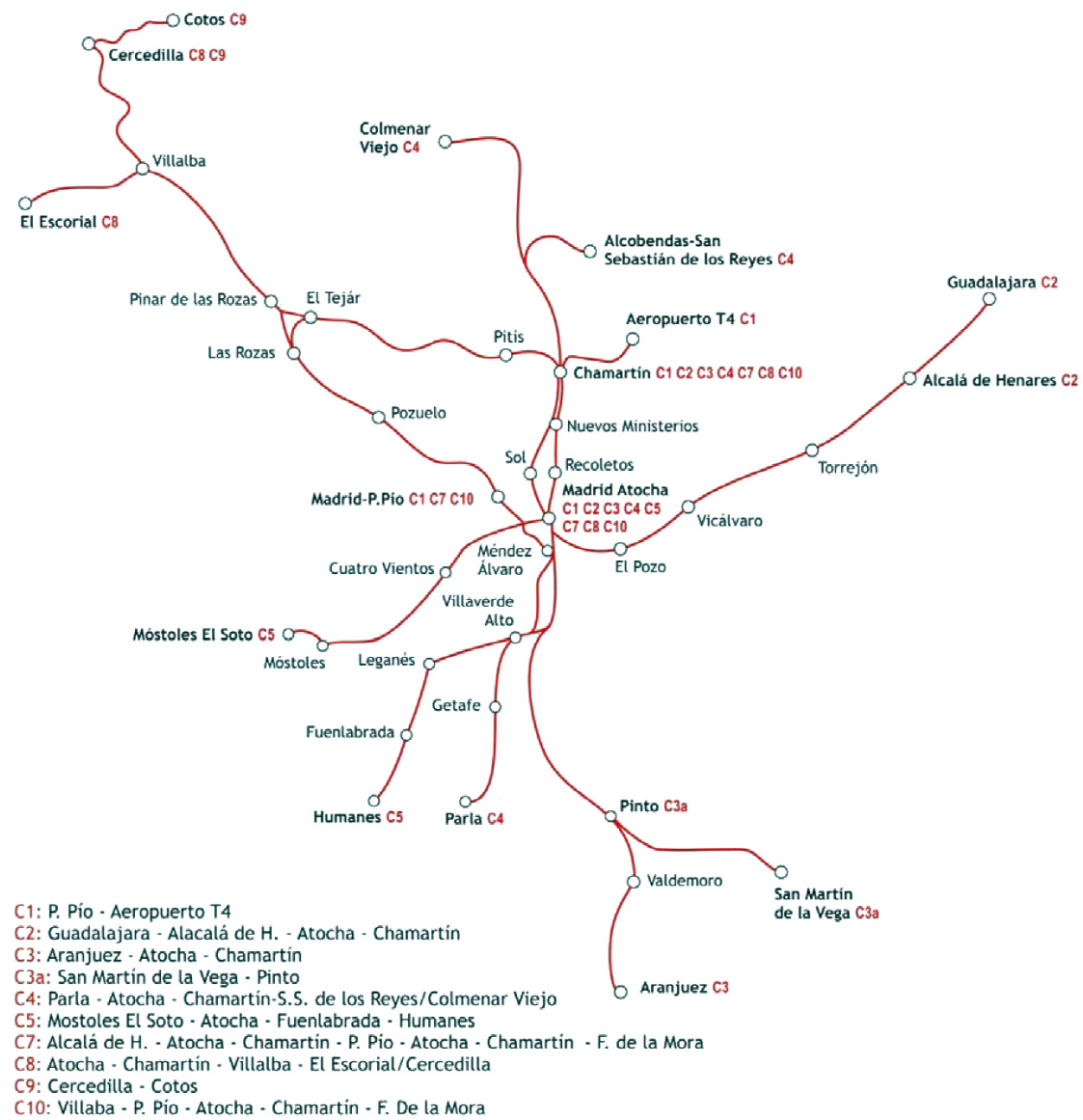

\section{Imagen 1}

Red de cercanías de Madrid

Fuente: OFE, 2015, pp. 124. 
En conjunto, cercanías multiplicó su producción, entre 1985 y 2013, por 3,3, un factor claramente superior al de las otras modalidades de transporte: Metro $(1,7)$, EMT $(0,9)$, concesiones de carretera $(1,7$, entre $1987-2013)$, autobuses interurbanos $(1,0)$ y autobuses urbanos $(0,8$, entre 1999-2013). Lógicamente, su cuota de mercado creció, pasando del 6,5\% en el primer año al $13,1 \%$ en el último; ahora bien, si se tiene presente que el Metro absorbía el 40,7\% y la EMT el 29,5\% no se puede calificar dicho avance más que como modesto puesto que seguía muy alejada de estos.

El comportamiento de cercanías viene explicado por la propia la evolución demográfica del área metropolitana de Madrid. Si hasta la década de los años sesenta el crecimiento de la oferta estuvo dirigido a satisfacer la demanda de la corona metropolitana, a partir de 1970 comienza a variar lentamente para hacer lo propio en el área metropolitana. Lo cual resulta comprensible si se tiene en cuenta que, mientras que la población de la capital se estanca, la de aquella inicia un crecimiento explosivo. Crecimiento que arranca en las localidades ubicadas o bajo la influencia del corredor de Extremadura, cuyas poblaciones, si bien habían crecido entre 1960 y 1970 en 113.179 habitantes, ganarán 408.168 habitantes entre 1970 y 1980. Mientras que las poblaciones de los corredores de Alcalá de Henares (185.332) y Andalucía (185.332) lo hicieron en menor cuantía, aunque también con fuerza. Durante la década de 1980 sigue siendo el corredor de Extremadura el que lidera el crecimiento con 129.876 habitantes; pero durante la última década del siglo tomará el testigo el corredor de Colmenar Viejo con 168.088 habitantes. Impulso este que se mantiene durante la primera década del siglo XXI, con otros 169.265 habitantes, aunque ahora comparte su liderazgo con los corredores de Andalucía (172.844) y, con menor intensidad, con el de Alcalá de Henares (107.486).

Los únicos datos disponibles para medir la evolución de la oferta, proporcionados por el CRTM, confirman esta reorientación hacia los corredores, primero del suroeste, luego del noreste, y finalmente del sur y noroeste. Así, el número de trenes ofrecido por sentido pasó de 498 en 1983 a 937 en 2002. En el primer año los tres corredores con más población absorbían el 85,7\% - Extremadura $(46,2)$, Alcalá de Henares $(23,1 \%)$ y Andalucía $(16,5 \%)$ Pero en 2002 ya solo representaban el 75,6\% pues Extremadura y Alcalá de Henares habían perdido, respectivamente, 9,5 y 2,4 puntos, mientras que el corredor de Colmenar Viejo había ganado un 8,3\%. Una evolución semejante se observa en cuanto a la oferta de plazas de transporte se refiere ${ }^{31}$.

${ }^{31}$ Hasta 2002 se contabilizaban las plazas ofrecidas en los servicios que transcurrían fuera de la Comunidad de Madrid, que venían a representar un 62,6\% del total. 


\section{Cuadro 2}

Viajeros medios subidos por corredor en un día laborable de marzo de 2013 en las principales estaciones de cercanías de Madrid

\begin{tabular}{lrr}
\hline Estaciones urbanas Madrid & 241.740 & $37,3 \%$ \\
Henares & 97.047 & $15,0 \%$ \\
Humanes & 80.878 & $12,5 \%$ \\
Parla & 57.889 & $8,9 \%$ \\
Móstoles & 50.995 & $7,9 \%$ \\
Norte & 44.781 & $6,9 \%$ \\
Noreste (A6) & 42.731 & $6,6 \%$ \\
Aranjuez & 31.419 & $4,9 \%$ \\
\hline Total & 647.480 & $100,0 \%$ \\
\hline
\end{tabular}

Fuente: CRTM, 1993.

Desde la perspectiva de la demanda se alcanzan, obviamente, conclusiones semejantes. En 1983 el 71,1\% del tráfico total (53,3 millones) se concentraba en las relaciones de Madrid Chamartín-Guadalajara (28,3\%), Aluche-Villaviciosa de Odón $(27,2 \%)$ y Madrid Atocha-Fuenlabrada $(15,6 \%)$. En 2013 los 647.480 viajeros medios subidos en un día laboral de marzo lo hacían mayoritariamente en las estaciones urbanas de Madrid $(37,3 \%)$, seguidos por los registros de los corredores de Henares (15\%) y Humanes $(12,5 \%)$.

\section{Barcelona}

\subsection{Contexto geográfico y poblacional}

Barcelona está ubicada en una llanura costera formada por los depósitos aluviales de los ríos Congost-Besòs y Llobregat. Hacia el interior la ciudad llega a las estribaciones de la llamada cordillera litoral, formada por las sierras Marina (de Montnegre a Sant Mateu) y Collserola, y el macizo del Garraf, con alturas comprendidas entre los 500 y 700 metros. La plana delimitada por la montaña y el mar es lo bastante grande como para albergar una ciudad de tamaño medio, incluso grande; pero no una gran conurbación. No obstante, el acceso al interior por los valles de esos ríos es 
relativamente fácil. De este modo, en pocos kilómetros se alcanza una planicie limitada al norte por la cordillera prelitoral, es decir, los macizos de Montseny, Sant Llorenç del Munt i Montserrat. En este espacio surgieron una cadena de poblaciones de tamaño regular; de norte a sur, Granollers, Terrasa, Sabadell, Rubí, Martorell, San Sadurní de Noya y Villafranca del Penedès. El principal, que no único, problema que deben resolver las redes de proximidad de Barcelona es la conexión de esas ciudades con la capital a través de los corredores de los ríos Besòs y Llobregat ${ }^{32}$.

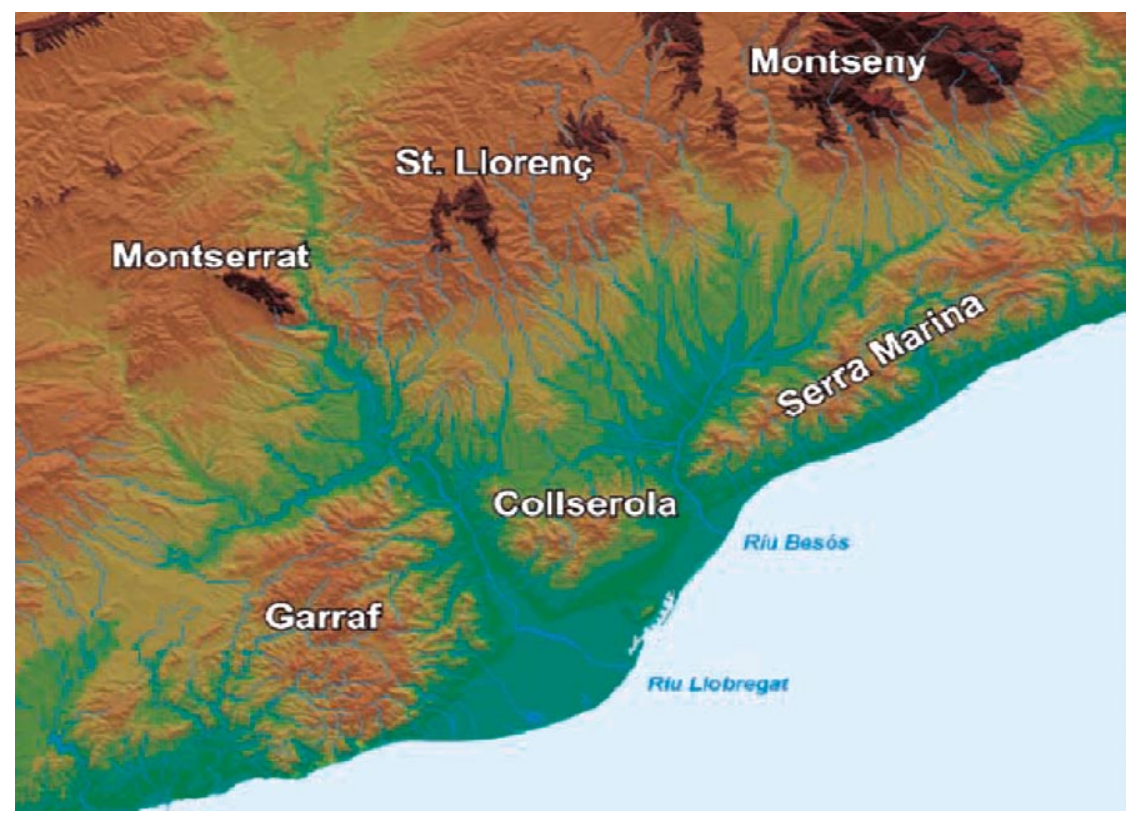

\section{Imagen 2}

Orografía del área metropolitana de Barcelona

Fuente: ATM, 2013a: 78.

Este problema se fue agrandando durante la segunda mitad del siglo XX conforme la ciudad y la periferia de Barcelona experimentaban un

32 ATM, 2013 pp. 7-13. 
fuerte crecimiento demográfico; aún mayor en esta que en aquélla. Entre 1950 y 2011 la población del Barcelonés - Barcelona y las localidades inmediatas, Hospitalet de Llobregat, Badalona, Santa Coloma de Gramenet y Sant Adrià del Besòs - pasó de 1,4 a 2,2 millones de habitantes; es decir, se multiplicó por 1,6. En cambio, la población del área metropolitana circundante pasó de 0,4 a 2,4 millones de habitantes ${ }^{33}$; es decir, se multiplicó por 5,8. De hecho, en las últimas décadas incluso ha habido un descenso de la zona central. Barcelona alcanzó su máximo histórico en 1981 con 1,76 millones de habitantes, según el censo de población de ese año; un nivel casi idéntico al señalado por el censo de 1970. Algo semejante se puede decir del Barcelonés, cuyos dos municipios interiores, Santa Coloma y Hospitalet, han sufrido una notable pérdida de población. En cambio, en el resto del área metropolitana normalmente ha aumentado la población, especialmente en el período anterior a 1970. Desde que comenzó el siglo XXI, el área metropolitana de Barcelona ha crecido levemente gracias a la inmigración extranjera. Hoy en día, su población total es dos veces la del Barcelonés, y tres veces la de capital ${ }^{34}$.

Aunque el crecimiento de la región no es, en esencia, distinto del de muchas grandes ciudades europeas, tiene la peculiaridad de haberse desarrollado en un espacio limitado. Debido a las barreras impuestas por la orografía, hoy en día el área urbana de Barcelona tiene una muy elevada densidad de población. El término municipal de Barcelona solo cuenta con 101,4 km² de extensión. Incluso si consideramos todo el Barcelonés apenas se alcanzan los $143 \mathrm{~km}^{2}$. Este reducido espacio alberga una población de 2,2 millones de habitantes, lo que otorga al conjunto una densidad de $16.000 \mathrm{hab} / \mathrm{km}^{2}$, que convierte a estos cinco municipios en la conurbación española más densamente poblada, y en una de las más densas de Europa. Dentro de ella, L'Hospitalet de Llobregat es la ciudad española de más de 50.000 habitantes con mayor densidad poblacional, $18.800 \mathrm{hab} /$ $\mathrm{km}^{2}$. Y eso a pesar de la pérdida de habitantes de las últimas décadas.

33 Tal y como se indica en la nota 3, el área metropolitana de Barcelona, como la de Madrid, se define a través de los criterios AUDES. Comprendería 95 localidades del área Barcelona-Vallès-Llobregat (donde se incluyen, por ejemplo, Granollers, Mataró, Manresa y Terrasa), y de las subáreas de Sant Boi, Castelldefels, Sant Vicenç dels Horts, Premiá, Martorell y Castellar del Vallès.

${ }^{34}$ Sobre el crecimiento urbano de Barcelona, Ferrer i Aixalá y Nel·lo i Colom, 1991 pp. 9-30. Sobre el concepto y proceso de suburbanización, Monclus, 1998. 


\subsection{La construcción de la red ferroviaria barcelonesa}

La construcción de este espacio altamente urbanizado se realizó sobre una red de pequeñas ciudades nacidas al calor de una temprana Revolución industrial. Debido a su tamaño y dinamismo, muchas de ellas se dotaron pronto de infraestructuras básicas de transporte que las conectaban entre sí y con la capital. A comienzos del siglo XX ya estaba terminada gran parte de la actual red ferroviaria convencional. Las dificultades del acceso llevaron a que en las inmediaciones de Barcelona las líneas corriesen paralelas, a menudo compartiendo plataforma, como sucedió entre Montcada y Barcelona en los ferrocarriles de Zaragoza y Granollers ${ }^{35}$.

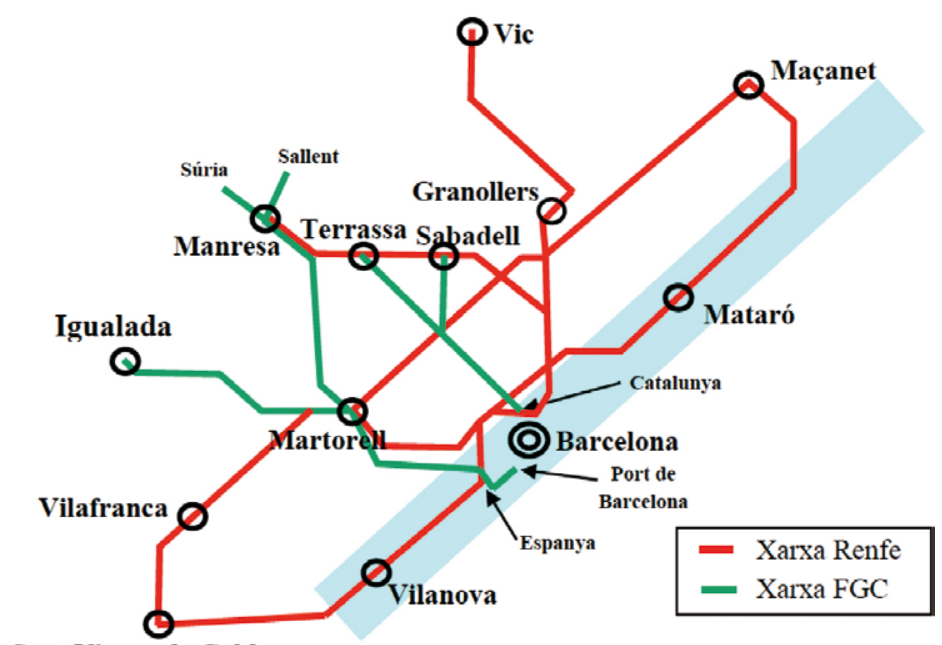

Sant Vicenç de Calders

\section{Figura 1}

Esquema de las líneas de cercanías en el Área urbana de Barcelona

Fuente: ATM, 2009, p. 116.

Esa red no fue diseñada para el transporte cotidiano de viajeros. Solo era el final de varias líneas de largo recorrido que replicaban el modelo

35 Pascual Domènech, 1999. Alcaide González, 2015 pp. 36-38. 
radial del país a escala regional. Barcelona era el punto de unión de dos elipses, el «ocho catalán». La línea procedente de Tarragona se desdoblaba en Sant Vicenç de Calders. Uno de los ramales avanzaba por el interior (Villafranca del Penedès y Martorell), y otro por la costa (Vilanova i la Geltrú y Castelldefels), para reunirse en Barcelona Sants. Por el norte, la línea de Girona se desdoblaba en Massanet de la Selva, también en un ramal interior (Granollers y Mollet) y otro costero (Mataró y Badalona), para volver a unirse en Barcelona-Sant Andreu Comtal. Las líneas de Lleida y Vic enlazaban con la parte septentrional del «vuit» en la bifurcació de Montcada, a pocos kilómetros de Barcelona.

Este trazado se completó con dos pequeñas redes de ancho no-ibérico. Como las anteriores, su principal finalidad era el transporte de mercancías, no el de viajeros. La primera de dichas líneas fue la que levantó la Compañía General de Ferrocarriles Catalanes (CGFC) en 1919 mediante la fusión de tres ferrocarriles menores, Manresa-Berga, Igualada-Martorell y Martorell-Barcelona, y la inmediata construcción, en 1924, de una vía que unía el primero con los otros dos. Así se formó una red de $190 \mathrm{~km}$ de extensión y forma de «Y», cuya vocación industrial se puso de manifiesto con la construcción, también en 1924, de un ramal a Suria para el transporte de sal y potasas desde las minas de esa localidad. La segunda red era la perteneciente a la Compañía de los Ferrocarriles de Cataluña (FCC), que a partir del viejo ferrocarril de Sarrià a Barcelona, y con tracción eléctrica, a comienzos del siglo XX extendió su ámbito hasta Sabadell y Tarrasa a través de Sant Cugat del Vallès. De este modo, se configuró una segunda «Y» más pequeña, $40 \mathrm{~km}$, al norte de la anterior. Dicha red se puede dar por concluida en 1925 con la inauguración de la estación de Sabadell-Rambla ${ }^{36}$.

Desde el principio, las mayores dificultades para el transporte ferroviario surgieron en la misma capital. En las últimas décadas del siglo XIX y primeras del Xx, Barcelona se fue convirtiendo en una ciudad densa en la que las vías de desarrollo seguían las comunicaciones periféricas, como en las ciudades-jardín de la línea de Sarria ${ }^{37}$. Pero el ferrocarril también fue generando importantes efectos barrera. A lo largo de las líneas principales se fueron levantando barriadas de chabolas o infraviviendas, en las que las mismas vías eran obstáculos al paso de personas, animales y

\footnotetext{
36 Alcaide González, 2015 pp. 44-45 y 131-135.

37 Prat, 1994 pp. 19-34.
} 
todo tipo de vehículos. Las primeras estaciones, como las de Plaza de Catalunya (Riera d'En Malla), Vilanova, o Francia (Paseo de la Aduana), pronto se vieron desbordadas por el crecimiento urbano. Las sobredimensionadas localidades cercanas fueron engullidas por la capital, y parte de la red suburbana pasó a ser urbana. Algunos tramos, como el de SarriáSan Gervasi del ferrocarril de Sarrià, fueron soterrados; pero esto no fue, ni mucho menos, lo habitual. El carácter caótico de todo el proceso hizo que los accesos a la capital fueran cada vez más complicados. Algunas de las soluciones puestas en marcha, como la construcción en trinchera del ferrocarril de la calle Aragó (la «carrer foradat»), la inauguración de las estaciones de mercancías de Morrot y La Sagrera, o la red de ferrocarriles internos del puerto, fueron resolviendo algunos de los problemas más urgentes; pero también tenían un elevado coste social pues generaban nuevos poblamientos marginales y efectos barrera. En varias zonas de Barcelona, más o menos coincidiendo con la antigua localidad de San Martí de Provençals, se fue configurando un espacio urbano de barriadas aisladas que comprometían los objetivos inicialmente previstos en el Ensanche ${ }^{38}$.

El primer intento serio dirigido a resolver estos problemas de forma global fue el Plan de Enlaces Ferroviarios de Barcelona de 1933, que no solo quería acabar con las ineficiencias del transporte, sino también eliminar muchas de esas zonas marginales. La situación económica de la República, la Guerra civil y la crisis de la postguerra paralizaron sus propuestas, pero gran parte fueron haciéndose realidad en las siguientes décadas, aunque con crecientes modificaciones. Por ejemplo, el Plan Ferroviario de 1944 preveía la construcción de dos túneles transversales en la ciudad, algo que no contemplaba el de 1933, y que se terminarían haciendo muchos años más tarde. Con el Plan de 1948 se llevó a cabo la construcción de un túnel en la avenida Meridiana, liberando el espacio superficial y eliminando varios pasos a nivel. El soterramiento de unas vías y la reunión de otras en un mismo trayecto fueron operaciones comunes en las décadas de 1950 y 1960. En el debe de estas realizaciones está la lentitud con que fueron llevadas. Por ejemplo, el cubrimiento de la carrer Aragó, ya previsto en el Plan de 1933, no se culminó hasta $1961^{39}$.

El todo caso, los proyectos fueron perfilando las líneas generales de lo que debía ser el nodo de comunicaciones de Barcelona, que poco tenía

38 Alcaide González, 2015 pp. 140-42 y 176-79.
39 Alcaide González, 2015 pp. 179-93 y 201-214. 
que ver con la desordenada malla del siglo XIX. El Plan de Enlaces Ferroviarios de 1966 ya era un bosquejo muy aceptable de esos nuevos accesos. En él se preveía la construcción de dos grandes estaciones en Sants y La Sagrera, con dos estaciones auxiliares en Can Tunis y Sant Andreu Comtal, respectivamente. Al igual que el Plan de 1933, el de 1966 contemplaba el soterramiento de la estación de Vilanova, lo que finalmente no se llevó a cabo pues esa estación acabaría desapareciendo. También contemplaba la eliminación de todas las instalaciones ferroviarias del litoral, lo que, esta vez sí sucedería, pero mucho más tarde, a raíz de las profundas modificaciones introducidas por el Plan Estratégico 2000 elaborado con la concesión de las Olimpiadas de 1992. Los tres elementos más determinantes de todo el proceso de reconstrucción de los accesos a Barcelona fueron: la apertura de la nueva estación de Sants en 1979, que se convertiría en la principal de Barcelona; la construcción de enlaces subterráneos entre Sants y las estaciones del noreste (Clot, San Andreu Comtal y La Sagrera); y la conversión de la estación de Francia en terminal de líneas de cercanías, eliminando las conexiones litorales con el $\mathrm{este}^{40}$. La figura 2 es un esquema del actual trazado ferroviario de Barcelona.

La construcción de esos enlaces, en buena parte subterráneos, fue una empresa de importancia crucial para el desarrollo ferroviario de Barcelona y Cataluña. Y también, casi, la única nueva. Desde 1924, solo se han construido tres grandes infraestructuras de transporte ferroviario en el área metropolitana de Barcelona. Primero, el ferrocarril de Martorell a Granollers, que cerraba por el interior la red de cercanías de Barcelona, y que incorporó un ramal entre Cerdanyola y la Universitat Autònoma y, más tarde, Martorell. Segundo, la línea entre el aeropuerto de El Prat de Llobregat y la estación de Sants. Tercero, por supuesto, la línea de Alta Velocidad Madrid-Barcelona, cuyo impacto sobre la ciudad fue enorme, pero que, por razones obvias, no es objeto de este trabajo. Hay cierta lógica en esta aparente desidia constructora. Ante todo, la existencia de una infraestructura previa en un territorio cuyo crecimiento superficial fue moderado por las razones indicadas. Pero también el hecho de que el verdadero problema ferroviario en Barcelona no era la falta de líneas, sino su ordenación y mejora. De hecho, a lo largo del período estudiado fueron cerradas un buen número de estaciones, en tanto se iban abriendo otras. Igualmente, se ce-

40 Alcaide González, 2015 pp. 217-223. Prat, 1994, pp. 26. 
rraron líneas ferroviarias al tráfico de viajeros; incluso se desmantelaron algunas completamente, sobre todo en el litoral. Muy a menudo esas decisiones se encuadran dentro de la rehabilitación de barrios, incluida la construcción de la Ciudad Olímpica. En realidad, la simple medición del número de kilómetros abiertos resulta un indicador poco afortunado del esfuerzo inversor si no tiene en cuenta la accesibilidad a las estaciones o la capacidad de las líneas. Volveremos sobre ello más adelante.

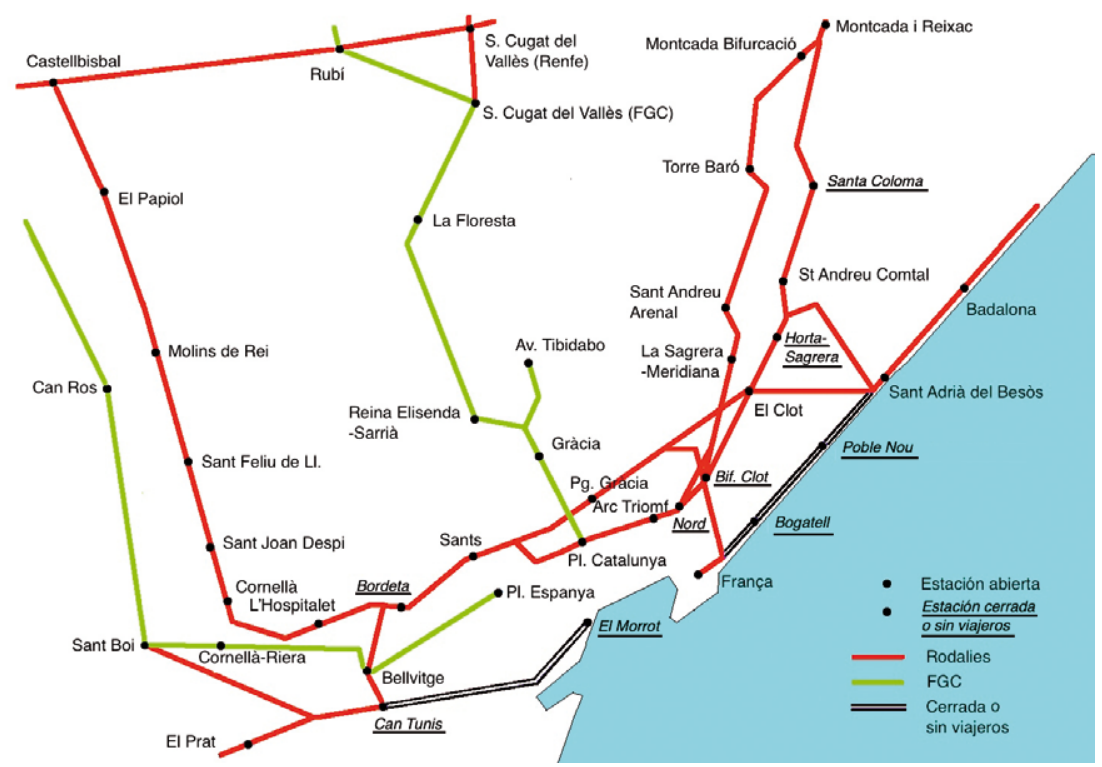

Figura 2

Esquema de las estaciones y líneas de cercanías en Barcelona

Nota: No es un esquema exhaustivo, no se recogen todas las estaciones.

Fuente: Miralpeix, 2010, pp. 38-42, Alcaide, 2015, pp. 201-228, y elaboración propia.

\subsection{El origen de los servicios de cercanías}

Como se ha indicado, ninguno de esos ferrocarriles se concibió como un servicio regular de cercanías. Las grandes arterias que venían de Lleida, Tarragona y Girona fueron diseñadas como vías de comunicación 
de larga distancia, por lo que su papel para el transporte diario de viajeros, que actualmente es el más importante, no fue relevante hasta hace unas pocas décadas. Algo semejante se puede decir del ferrocarril de Vic y Puigcerda, el antiguo minero de Sant Joan de las Abadesses, o de los ferrocarriles de ancho no-ibérico que enlazaban el Vallès Occidental, el Bages y la Anoia con la capital. Ni siquiera el relativamente reciente ferrocarril de Martorell a Granollers (1985), la actual línea 8 de Rodalies, tuvo su razón de ser en el tráfico de viajeros. Esa línea no es más que la adaptación del ferrocarril de El Papiol a Mollet, construido unos años antes para el transporte de mercancías que no tenían que entrar en la ciudad. No menos significativo, aunque irrelevante desde una perspectiva económica, es el hecho de que el actual Ferrocarril del Bajo Llobregat, el antiguo «Catalanes» de la CGFC, al día de hoy sigue transportando sales y potasas desde Suria.

Sin embargo, mucho antes de que se resolvieran los problemas de conexión dentro de la ciudad de Barcelona, operaba un verdadero servicio de cercanías. El cuadro 3 recoge el número de trenes de viajeros de servicio regular en cinco líneas con destino u origen en Barcelona en cuatro años: 1961, 1970, 1980 y 1986. Las estaciones de partida/destino de los trenes (Tarrasa tiene dos vías de acceso) son las principales localidades de la corona externa del área urbana, cuatro ciudades distantes del centro de Barcelona menos de $30 \mathrm{~km}$. Obviamente, no todos los trenes de viajeros que se recogen en el cuadro eran verdaderos cercanías, pues algunos tenían una procedencia o destino mucho más lejano. Y tampoco todos los viajeros de esos trenes podrían calificarse como commuters. Con todo, el hecho de que el número de trenes caiga rápidamente a partir de esas estaciones es un indicador muy claro de que, básicamente, estamos ante servicios de cercanías. Es más: todos los trenes de una de esas líneas, la de mayor tráfico, Sarrià-Sant Cugat-Tarrasa, deben calificarse como tales pues ese ferrocarril de vía estrecha no tenía más recorrido. La comparación con las cercanías de Madrid es elocuente. Solo esa línea movía en 1961 tantos trenes como el conjunto de las recogidas en el cuadro 1, que resume los principales (y supuestos) cercanías de Madrid en 1965. Y que, como se señaló, probablemente incluyan muchos trenes de largo recorrido. La existencia de ese temprano servicio también ha sido puesta de relieve por Marta Miralpeix ${ }^{41}$ para el período 1950-1970 a partir de la revisión de las tablas de horarios

${ }^{41}$ Miralpeix García, 2010,pp. 58-62. 
(cuadro 4). Es significativo que los servicios de cercanías eran ofertados en hojas diferentes a las de los trenes regionales. Comparando las frecuencias de dichos trenes en 1950, 1965 y 1976, se observa un crecimiento de los de la primera hora de la mañana, entre las siete y las nueve.

\section{Cuadro 3}

Número de trenes de viajeros en servicio regular

\begin{tabular}{lcccc}
\hline & 1961 & 1970 & 1980 & 1986 \\
\hline Granollers & 23 & 30 & 41 & 50 \\
Mataró & 53 & 57 & 44 & 66 \\
Terrasa (por Cerdanyola) & 28 & 27 & 46 & 50 \\
Terrasa (por Sant Cugat del Vallès) & 60 & 63 & 83 & 90 \\
Martorell & 12 & 36 & 33 & 34 \\
\hline
\end{tabular}

Fuente: Batlle y Gargallo, 1989, pp. 293-297.

\section{Cuadro 4}

Frecuencias en el servicio de cercanías hacia Barcelona entre las siete y las nueve de la mañana en Rodalies-Renfe.

Minutos

\begin{tabular}{lccccc}
\hline & 1950 & 1965 & 1976 & 1984 & 1991 \\
\hline C1 (Mataró) & 30 & 15 & 20 & 15 & 10 \\
C2 oeste (Vilanova) & & & & 20 & 12 \\
C2 este (Granollers) & & 60 & 45 & 30 & 15 \\
C3 (Vic) & & & & 30 & 20 \\
C4 sur (Martorell) & 30 & 60 & 20 & 30 & 10 \\
C4 norte (Tarrasa) & 30 & & & \\
\hline
\end{tabular}

Fuente: Miralpeix García, 2010, p. 63.

La existencia de ese temprano servicio de cercanías debe ponerse en relación con el fuerte crecimiento demográfico de Barcelona y su área metropolitana en las décadas de 1960 y 1970 . Pero es relevante que durante las dos siguientes décadas, cuando Barcelona había alcanzado su máximo his- 
tórico e iniciaba un declive, el número de trenes y viajeros siguió aumentando. Esa mayor demanda de transporte se ha producido tanto en el número de usuarios como en la distancia recorrida. Según las encuestas de movilidad obligada elaboradas por la Generalitat de Catalunya, entre 1981 y 2006 los desplazamientos dentro de la propia de Barcelona incluso descendieron un $2,4 \%$, un porcentaje que, no obstante, es bastante menor que el de la misma población, un 11,3\%. En cambio, la movilidad entre la «segunda corona» de la región metropolitana - las localidades periféricas de la región metropolitana - y Barcelona aumentaron un 353,7\% ${ }^{42}$. En un primer momento el transporte privado fue desplazando al colectivo en el conjunto de la movilidad. Sin embargo, desde 1996 se observa una estabilización. En torno al $25 \%$ de los desplazamientos actuales en la Región Metropolitana de Barcelona se realizan en transporte colectivo, porcentaje que asciende al $33 \%$ en la movilidad obligada. Así pues, la demanda de servicios de transporte ferroviario crece conforme lo hace la población del área suburbana. Este crecimiento en la demanda de servicios de transporte público, en buena parte ferroviario, es coherente con lo sucedido en Madrid y en muchas capitales europeas. Para muchos usuarios, la mayor demanda general de movilidad y los problemas de congestión de las redes viarias convirtieron al ferrocarril en un medio de transporte preferible al automóvil ${ }^{43}$.

De modo consecuente, a lo largo de ese período se produjo una sustancial mejora de la oferta de transporte. Según Marían Fernandez Cano desde 1975 hubo un «salto de escala» en la accesibilidad de la Región Metropolitana (reducida) de Barcelona. En las décadas de 1970 y 1980 la accesibilidad media en esa zona habría caído de 60,65 minutos en 1972 a 50,53 en 1985 , y a 47,21 en $1993^{44}$. Dada la inexistencia de nuevas líneas hasta 1982 (y pocas más en los años siguientes), esa mejora debe atribuirse a una mayor dotación de medios, así como a la mejora de las infraestructuras en la misma Barcelona, tal y como hemos visto.

\subsection{Situación actual}

Actualmente, Barcelona cuenta con ocho líneas de cercanías o «rodalies». Seis de ellas están gestionadas por Renfe Operadora: Molins del

\footnotetext{
42 ATM, 2013a, pp. 95-97, y 2013b, pp. 63-64.

43 ATM, 2013a, pp. 95-97 y 2013b, pp. 63-64.

44 Fernández Cano, 2009 pp. 88-108.
} 
Rei-Maçanet, Sant Vicenç-Maçanet, L'Hospitalet-Vic, Sant Vicenç-Manresa, Sant Andreu Arenal-Cerdanyola Universitat, y Martorell-Granollers Centre. Y otras dos por Ferrocarrils de la Generalitat de Catalunya, las líneas Barcelona-Vallès y Llobregat-Anoia. Los tramos de mayor densidad son los del interior de Barcelona y los que unen la capital con Sant Vicenç de Calders (por la costa), Martorell, Terrasa, Maçanet y Mataró. Con respecto a la situación de partida en las décadas de 1960 y 1970, y a partir de los datos de frecuencias y número de trenes, el mayor crecimiento de la demanda ha tenido lugar en la línea costera de Sant Vicenç de Calders y Vilanova i la Geltrú con Barcelona. Pero sin que ello signifique que las conexiones con el interior hayan decaído.

En total, las cercanías catalanas constan de $609,8 \mathrm{~km},(467,2 \mathrm{~km}$ de Rodalies y 142,6 km de FGC), de los que 569 ya existían en $1975^{45}$. La reducida construcción de nuevas vías desde 1925 hasta 1982 contrasta con las inauguraciones realizadas en Madrid en esos años. Este hecho constituye la base de las reivindicaciones de una parte de la clase política catalana; pero es un argumento muy pobre ${ }^{46}$. Existiendo una densa red ferroviaria en un espacio relativamente pequeño y limitado por la orografía y el mar, la necesidad de construir nuevos accesos a la capital era prácticamente nula desde comienzos de siglo. De hecho, y a pesar de la intensa construcción de vías en Madrid, los indicadores de intensidad de la red ferroviaria de las dos ciudades son muy parecidos. Por ejemplo, el índice conjunto de Longitud, Población y Superficie (LPS) estimado por Manel Larrosa y Silvia Berhend a partir de los datos de 1998-1999, otorgaba a la región metropolitana de Barcelona un valor de 434, casi idéntico a la de Madrid, $433^{47}$. Rafael Alcaide ${ }^{48}$ obtiene un resultado coherente con el anterior con datos de 2007. El número de habitantes por estación/apeadero en la Entidad Metropolitana de Barcelona era de 13.073, mientras que en Madrid era de 13.816. Con relación a la superficie, en la Entidad Metropolitana de Barcelona había 0,76 estaciones/apeadero por 10.000 habitantes, y 0,72 en Madrid. Parece fuera de toda discusión que la oferta de infraestructuras viarias en las dos capitales es similar.

45 ATM 2013 b pp. 26-30. Hay que notar que la red total de FGC suma $184 \mathrm{~km}$. 2006.

46 Argumento también empleado para períodos más recientes: Tarragó y Mussons,

47 Larrosa, 2003, p. 74.

48 Alcaide, 2008. 
Otra cosa es que las inversiones hayan satisfecho las necesidades de movilidad de la población. El «nudo gordiano» de la red ferroviaria barcelonesa se encuentra en la misma capital, en los enlaces entre la estación de Sants, al suroeste de la ciudad, y las estaciones de las que parten los ferrocarriles del norte y la costa: Clot, Sant Andreu Comtal, Sant Andreu del Arenal, Torre Baró, y Montcada bifurcación, así como la estación de Francia. Actualmente existen dos túneles que enlazan Sants con la bifurcación de Vilanova - el túnel de la Plaza de Catalunya - y con la bifurcación de Aragó - túnel del Paseo de Gracia-. En ambos el tráfico está congestionado. Esto lleva a los maquinistas a reducir las velocidades, y hasta detener los trenes, generando demoras en el servicio ${ }^{49}$. Las encuestas de calidad elaboradas por Renfe ponen de manifiesto la mala opinión que los barceloneses tienen de este servicio, y que contrasta con la buena que tienen del que ofrece FGC en sus líneas, las cuales desembocan en la ciudad sin atravesarla. La única solución posible a largo plazo sería la construcción de un tercer túnel longitudinal este-oeste; pero al día de hoy ni siquiera existe un proyecto en firme.

Una posible explicación de la falta de nuevas inversiones en esta red - que sí que se ha dado en un proyecto estrella como el AVE-, se encuentra en la inexistencia de una verdadera y única autoridad de transporte de cercanías. Desde finales de la década de 1970 la red se encuentra gestionada por dos entidades que dependen orgánicamente de administraciones públicas diferentes y, no pocas veces, enfrentadas. Por un lado, la red de vía ancha, que después de sucesivas fusiones y adquisiciones había terminado en manos de la compañía Norte, y que fue nacionalizada y traspasada a Renfe en 1941, empresa pública que se ha ocupado de su explotación hasta 2005. Entonces se decidió separar la gestión de la infraestructura de la explotación, que quedaron a cargo de dos nuevas empresas pública, Adif y Renfe Operadora. En 2009 el Gobierno cedió las competencias de Rodalies Barcelona al gobierno catalán, pero tanto la infraestructura como el material móvil siguieron en manos de sus antiguos propietarios, es decir, Adif y Renfe Operadora. Así pues, aunque formalmente el Govern es responsable de este servicio, en la práctica sus competencias apenas alcanzan a regular horarios y tráficos, y adaptarlos a la otra gran red de cercanías, la de FGC. Esta se encuentra formada por las

49 ATM, 2013 pp. 103-104. Martínez Sánchez, 2006, pp. 93-94. Gutiérrez, 2015 pp. 25-30. Puente, 2016. 
dos redes de ferrocarriles de ancho no-ibérico que fueron traspasados a Feve en 1977, y dos años después al nuevo gobierno catalán. A diferencia de la red estatal, el Govern ha realizado una considerable inversión, lo que ayuda a explicar por qué actualmente el servicio ofrecido por FGC es muy superior al de Renfe, a decir de las encuestas de los usuarios ${ }^{50}$.

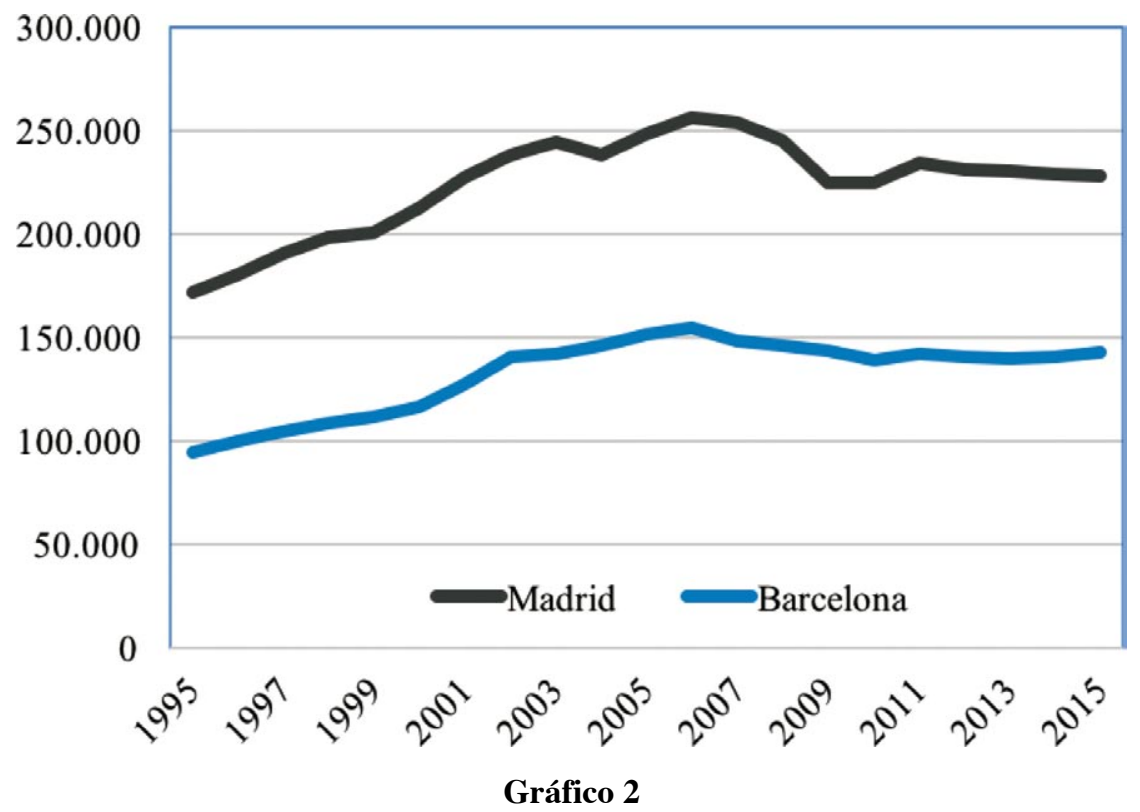

Viajeros anuales de Madrid y Barcelona (miles)

Nota: Las cifras de Barcelona incluyen Rodalies y FGC.

Fuente: Ministerio de Fomento (www fomento.gob.es),

FGC Ayuntamiento de Barcelona (www.bcn.cat).

\section{Conclusiones}

El gráfico 2 recoge la evolución del transporte de viajeros en cercanías (Renfe y FGC) desde 1995, año desde el que disponemos de cifras

50 Gutiérrez, 2015. Puente, 2015. Alcaide, 2017. 
completas homogéneas. La tendencia de las dos series, Madrid y Barcelona, ha sido creciente hasta poco antes del comienzo de la crisis. Siguió una notable caída y una cierta estabilización desde 2010. En conjunto, Barcelona ha ido ganando importancia con respecto a Madrid, sobre todo hasta 2004. Y ello a pesar de que su crecimiento demográfico ha sido menor. Todo ello sugiere que la oferta de servicios no ha sido muy diferente. $\mathrm{O}$ al menos, que las restricciones derivadas de la menor inversión en nuevas líneas en Barcelona no han supuesto, hasta ahora, un obstáculo insalvable para el desarrollo del servicio.

Atendiendo a la accesibilidad en lugar del producto, Cercanías de Madrid y Rodalies-FGC de Barcelona hoy en día disponen de una dotación de infraestructuras similar. De nuevo, el contexto geográfico y demográfico es importante para hacer comparaciones, máxime cuando, en realidad, las dos áreas urbanas tienen poco en común. La de Madrid acoge 1,7 millones de personas más que la de Barcelona, es decir, es un $27 \%$ más grande. Pero, sobre todo, el territorio por el que se extiende es mucho más grande: 4.900 frente a $1.750 \mathrm{~km}^{2}$. Lógicamente, la densidad de población es mucho mayor en Cataluña; siendo muy considerable en el llamado Barcelonés.

Por otro lado, Barcelona y Madrid partían de un pasado histórico muy diferente. Barcelona y sus alrededores fue la primera gran región española en industrializarse. Hacia 1950 existía un cinturón de ciudades medianas surgidas al calor de su temprana Revolución industrial, unidas con la capital mediante una red centralizada - el vuit català - que no se construyó para atender las necesidades de transporte características de las cercanías, pero que empezaba a ser empleada como tal. Los principales problemas de desarrollo de ese servicio estaban en la misma capital, donde la ausencia de una mínima planificación urbana había hecho que el acceso a la ciudad fuera lento y complicado. Este problema quizás fuera soportable para el transporte de mercancías a larga distancia, pero era inadmisible para el diario de personas. La lenta construcción de infraestructuras capitalinas fue paliando el problema de forma paralela a cómo iba creciendo el servicio regular de viajeros. En fin, en los años 80, cuando Barcelona capital había dejado de crecer, se produjo un incremento extraordinario de los servicios de transporte basado en la urbanización de la periferia y la aparición de nuevas demandas de transporte.

El desarrollo industrial de Madrid fue mucho más tardío y concentrado que el de Barcelona. Esto explica que su servicio de cercanías también fuera mucho más modesto, prácticamente irrelevante hasta el mismo 
fin de la Dictadura. Es cierto que Madrid disfrutaba de los beneficios de una red centralizada, pero esta apenas era empleada para el servicio regular de viajeros. La situación experimentó un giro en los años comprendidos entre 1978 y 1986, cuando se abandonó definitivamente la vieja noción del ferrocarril madrileño de cercanías como una suerte de enlaces entre Madrid y la sierra, y se empezó a tener conciencia de la importancia del servicio regular. Desde mediados de la década de 1980 un cambio en la política de transporte, así como una notable mejora de la calidad y cantidad del servicio lograda mediante una fuerte inversión pública en la infraestructura viaria, hizo que el número de viajeros se incrementará de forma continua. A ese fuerte aumento del tráfico también contribuyó el crecimiento tanto de Madrid como, sobre todo, de su periferia urbana.

Así pues, esta es una historia con final feliz. Si, pese a todas las diferencias históricas, geográficas y demográficas, la evolución de las cercanías de Madrid y Barcelona ha avanzado hacia la convergencia, solo cabe concluir que los responsables políticos estatales y autonómicos han logrado satisfacer de forma equilibrada las necesidades de transporte de las dos conurbaciones. Aunque, por supuesto, nada asegura que dicha evolución se mantenga en el futuro.

\section{Referencias bibliográficas}

AlCAIDE GonZÁLEZ, Rafael, «El ferrocarril como elemento estructurador de la morfología urbana: El caso de Barcelona 1848-1900». Scripta Nova. Revista Electrónica de Geografía y Ciencias Sociales, IX(194[65]), 2005.

ALCAIDE GonZÁLEZ, Rafael, «La evolución de las redes de transporte público ferroviario de Madrid y Barcelona 1997-2006. Una reflexión sobre el territorio.» Diez años de cambios en el Mundo, en la Geografía y en las Ciencias Sociales, 1999-2008. Actas del X Coloquio Internacional de Geocrítica, Universidad de Barcelona, 26-30 de mayo de 2008. <http://www.ub.es/ geocrit/-xcol/279.htm>

AlCAIDE GonZÁlez, Rafael, El ferrocarril en la ciudad de Barcelona (18481992): desarrollo de la red e implicaciones urbanas, Fundación de los Ferrocarriles españoles, 2015.

AlCAIDE GonZÁLEZ, Rafael, «Ferrocarrils de la Generalitat de Catalunya: cuatro décadas de vocación de servicio público», VII Congreso de Historia Ferroviaria, Valencia, 18-20 de octubre de 2017.

Aldama, Enrique, «Red Arterial de Madrid. Estudio de tráfico», Boletín de Información del Ministerio de Obras Públicas, 77, 1964, pp. 14-22; 
Aldama, Enrique, «Red Arterial de Madrid. Estudio de tráfico», Boletín de Información del Ministerio de Obras Públicas, 91, 1965, pp. 6-9.

Autoritat Del Transport Metropolità (ATM), Pla director de mobilitat de la Regió Metropolitana de Barcelona 2008-2012, Barcelona, 2009.

Autoritat DEL Transport Metropolità (ATM), Pla director de mobilitat de la Regió Metropolitana de Barcelona 2013-2018, Barcelona, 2013a.

Autoritat DEL TRAnSPORT METROPOltà (ATM), Pla Director d'Infraestructures del transport públic col.lectiu de la regió metropolitana de Barcelona 20112020. Barcelona, 2013b.

Batlle y Gargallo, Lluis, El transport ferroviari a Catalunya. Barcelona, Generalitat de Catalunya, 1989.

BoIX, Rafael, y Paolo VENERI, «Metropolitan Areas in Spain and Italy» IERMB Working Paper in Economics, n. ${ }^{\circ}$ 09.01, March 2009.

BRIÑIS, Carlos María, «El transporte público de superficie en Madrid», Boletín de Información del Ministerio de Obras Públicas, 112, 1967, pp. 24-27.

CAsas Torres, José Manuel, y María Pilar GONZÁLEZ YANCI, Los accesos ferroviarios a Madrid: su impacto en la geografía urbana de la ciudad, Madrid, Instituto de Estudios Madrileños, 1977.

Cayón, Francisco, Domingo CuÉllar y Francisco Polo (coordinadores), Madrid en sus Cercanías, Un recorrido por la metrópoli y su ferrocarril, Fundación de los Ferrocarriles Españoles, Madrid, 2003.

Comisión de Planeamiento y Coordinación del Área Metropolitana de MaDRID (COPLACO), Estudio monográfico sobre el transporte en la provincia de Madrid, Madrid, 1971.

Consorcio Regional de Transportes de Madrid (CRTM), Memoria de 1992, Madrid, 1993.

Consorcio Regional de Transportes De Madrid (CRTM), Demanda de Transporte público colectivo, Madrid, 2013.

Esteras GonzÁlez, Matías J., «Las Cercanías ferroviarias de Madrid», Revista del Ministerio de Obras Públicas y Transportes, 50, 1991, pp. 5-38.

FERrer i AixAlÁ, Amador y Oriol Nel-LO I COLOM, «Barcelona: la transformació d'una ciutat industrial» Papers: Regió Metropolitana de Barcelona, 3, 1991, pp. 9-30.

FERnÁndez CANO, Marian, Anàlisi de l'evolució de l'accessibilitat a la xarxa ferroviària de Barcelona. Universitat Politècnica de Catalunya, Barcelona, 2009.

FERnÁNDEZ-MAYORALAS FERnÁNDEZ, Gloria, El Transporte de viajeros por ferrocarril en la Comunidad de Madrid, Tesis Doctoral, Universidad Complutense de Madrid, 1989.

FiguerOA, Antonio, «La red arterial de Madrid», Boletín de Información del Ministerio de Obras Públicas, 114, 1958, pp. 4-22.

GonZÁlez MÁrquez, Manuel «Coches de viajeros de vía ancha (1). Los coches de dos ejes». Revista Maquetren, n. ${ }^{\circ}$ especial 1,1996 
Rafael Barquín Gil, Miguel Muñoz Rubio

García Palomares, Juan Carlos, «Pautas de la movilidad en el área metropolitana de Madrid», Cuadernos de Geografía, 81-82, 2007, pp. 1-23.

García PÉREZ, Antonio, Indalecio Prieto y los enlaces ferroviarios de Madrid, Madrid, Fundación Indalecio Prieto, 2013.

GonZÁLEZ YANCI, Pilar, «El ferrocarril mantiene su protagonismo en la evolución urbana de Madrid: el Pasillo Verde y la operación Chamartín» Estudios Geográficos, 73, 273, 2012, pp. 483-506.

GutiÉRrez, Iván, «Cercanías Madrid ha recibido en 30 años el doble que Rodalies». El Economista-Catalunya, 7 de septiembre de 2015: 25-30.

GutiérRez Puebla, Javier y Juan Carlos GARCÍA PALOMARES, «Cambios en la movilidad en el área metropolitana de Madrid: el creciente uso del transporte privado», Madrid, Anales de Geografía, 25, 2005, pp. 331-351.

INECO, Estudio Socioeconómico sobre los usuarios del transporte, Madrid, 1978.

LARrosA, Manel, «Xarxa viària a la regió metropolitana de Barcelona. Un balanç.» Papers, Regió Metropolitana de Barcelona, 38, 2003, pp. 63-85.

Lerma RuedA, Antonio, «Las Cercanías Ferroviarias de Madrid en perspectiva histórica (1955-1994)» II Congreso de Historia Ferroviaria, Aranjuez, 2001.

MARISTANY I GILBERT, Eduardo, Impresiones de un viaje por los Estados Unidos, Imprenta Henrich, Barcelona, 1905).

MARTínez SÁnchez, José Antonio, Anàlisi de la xarxa ferroviària de la RMB. Universitat Politècnica de Catalunya, Barcelona, 2006.

Ministerio DE FOMENTO, Plan de infraestructuras ferroviarias de cercanías de Barcelona 2008-2015, Barcelona, 2009.

Miralpeix García, Marta, El ferrocarril en la Región Urbana de Barcelona: Análisis del desarrollo de la red ferroviaria y de metro (1848-2009) y modelización de su explotación (1950-2009). Universitat Politècnica de Catalunya, Barcelona, 2010.

Monclus, Francisco Javier, Suburbanización y nuevas periferias. Perspectivas geográfico-urbanísticas en Monclus, Francisco Javier, y Giuseppe DEMATTEIS (eds.), La ciudad dispersa. Suburbanización y nuevas periferias, Centre de Cultura Contemporània de Barcelona, Barcelona, 1998.

ObSERVATORIo DEl Ferrocarril En EsPaña (OFE), Informe 2011 Documento de trabajo diciembre 2012, Fundación de los Ferrocarriles Españoles, Madrid, 2012.

Pascual Domènech, Pere, Los caminos de la era industrial, Universidad de Barcelona, Barcelona, 1999.

Plan de Cercanías de Madrid de 1971, Boletín de Información del Ministerio de Obras Públicas, 160, 1971, pp. 17-30.

PRAT, Jordi, «El sistema ferroviario en la configuración de la región de Barcelona»». Papers: Regió Metropolitana de Barcelona: Territori, Estratègies, Planejament, 16, 1994, pp. 19-34. 
PuENTE, Arturo, «Por qué las Rodalies catalanas funcionan tan mal (y por qué seguirán haciéndolo)»<http://www.eldiario.es/catalunya/trenes-rodaliesCatalunya_0_483652488.html 2/2/2016.

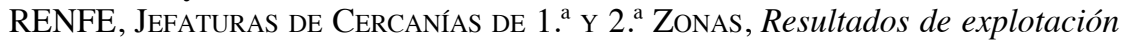
de las cercanías de Madrid. Año 1983, Madrid, 1984.

RENFE E INECO, Actualización de las Cercanías de Madrid, Madrid, 1977.

Río, Luis del, «El servicio de viajeros en los enlaces ferroviarios de Madrid», Boletín de Información del Ministerio de Obras Públicas núm. 2, 1958, pp. $10-19$ у p. 207.

RocA, Cayetano, «El transporte en Madrid», Ciudad y Territorio números 2-3, Madrid, 1976, pp. 121-134.

Ruiz GonzÁlez, Francisco, Proyecto AUDES - Áreas Urbanas de España. Universidad de Castilla-La Mancha. <http://alarcos.esi.uclm.es/per/fruiz/ audes/>, 2011.

SofreraIL, Étude des perspectives de trafic ferroviaire du Grand Madrid, Sofrerail, Paris, 1967.

TARRagó, Anaís, y Joan María Mussons, La dotació y la inversió pública en infraestructures a la província de Barcelona 1991-2002. IERMB, Barcelona, 2006.

VELARDE Fuertes, Juan, «La gestión económica de Indalecio Prieto en el Ministerio de Obras Públicas», discurso leído en la Real Academia de Ciencias Morales y Políticas el 21-XI-1883. 
Rafael Barquín Gil, Miguel Muñoz Rubio

Anexo 1. Población en Barcelona y Madrid entre 1950 y 2011

\begin{tabular}{|c|c|c|c|c|c|c|c|}
\hline Población & 1950 & 1960 & 1970 & 1981 & 1991 & 2001 & 2011 \\
\hline Área Metrop Barcelona & 1.854 .676 & 2.445 .991 & 3.426 .246 & 4.053 .418 & 4.095 .198 & 4.126 .319 & 4.660 .716 \\
\hline Barcelona capital & 1.280 .179 & 1.557 .863 & 1.745 .142 & 1.754 .900 & 1.681 .132 & 1.503 .884 & 1.611 .013 \\
\hline Barcelonés & 1.438 .921 & 1.821 .324 & 2.281 .171 & 2.453 .317 & 2.336 .215 & 2.093 .670 & 2.240 .522 \\
\hline A. M. Barna sin capital & 574.497 & 888.128 & 1.681 .104 & 2.298 .518 & 2.414 .066 & 2.622 .435 & 3.049 .703 \\
\hline Área Metrop Madrid & 1.830 .071 & 2.540 .197 & 3.748 .475 & 4.705 .192 & 5.011 .705 & 5.391 .407 & 6.374 .963 \\
\hline Madrid capital & 1.618 .435 & 2.259 .931 & 3.146 .071 & 3.188 .297 & 3.084 .673 & 2.938 .723 & 3.186 .595 \\
\hline A. M. Madrid sin capital & 211.636 & 280.266 & 602.404 & 1.516 .895 & 1.927 .032 & 2.452 .684 & 3.188 .368 \\
\hline Crecimiento anual & & $1960-1950$ & $1970-1960$ & 1981-1970 & 1991-1981 & 2001-1991 & 2011-2001 \\
\hline Área Metrop Barcelona & & 2,81 & 3,43 & 1,54 & 0,10 & 0,08 & 1,23 \\
\hline \multirow[t]{2}{*}{ A. M. Barna sin capital } & & 4,45 & 6,59 & 2,88 & 0,49 & 0,83 & 1,52 \\
\hline & & & & $1981-1950$ & & & 2011-1981 \\
\hline Área Metrop Barcelona & & & & 2,55 & & & 0,47 \\
\hline \multirow[t]{2}{*}{ A. M. Barna sin capital } & & & & 4,57 & & & 0,95 \\
\hline & & $1960-1950$ & $1970-1960$ & $1981-1970$ & 1991-1981 & 2001-1991 & 2011-2001 \\
\hline Área Metrop Madrid & & 3,33 & 3,97 & 2,09 & 0,63 & 0,73 & 1,69 \\
\hline \multirow[t]{2}{*}{ A. M. Madrid sin capital } & & 2,85 & 7,95 & 8,76 & 2,42 & 2,44 & 2,66 \\
\hline & & & & $1981-1950$ & & & 2011-1981 \\
\hline Área Metrop Madrid & & & & 3,09 & & & 1,02 \\
\hline A. M. Madrid sin capital & & & & 6,56 & & & 2,51 \\
\hline
\end{tabular}

Nota: Para la delimitación de las áreas metropolitanas, Audes (Ruiz González, 2011). Ver notas a pie de página 3 y 33 .

Fuente: Censos de población de los respectivos años y elaboración propia. 


\section{Datos de los autores}

Rafael Barquín. Rafael Barquín (Burgos, 1966) es doctor en Historia Económica por la Universidad de Burgos y profesor titular en la Facultad de Ciencias Económicas y Empresariales de la UNED. Imparte varias asignaturas de Historia Económica desde hace 25 años, y más recientemente también de Estructura y Política Económica. Sus principales líneas de investigación se sitúan en la Historia Ferroviaria de España o están estrechamente vinculadas con ella, como la integración de los mercados agrícolas o los efectos del ferrocarril sobre el crecimiento urbano o la alfabetización. Es editor de la revista Transportes, Servicios y Telecomunicaciones. Más información en www.uned.es/cee/rbarquin

Miguel Muñoz Rubio (mmrubio59@gmail.com - https://orcid.org.0000-0001-9726910X). Miguel Muñoz (Madrid, 1959) es Doctor en Historia Contemporánea por la Universidad Autónoma de Madrid e investigador de la Fundación de los Ferrocarriles Españoles. Ha sido director de la Biblioteca Ferroviaria, del Archivo Histórico Ferroviario y del Museo del Ferrocarril de Madrid. Ha sido profesor de Historia Económica Mundial e Historia Económica de España en la Facultad de Ciencias Económicas y Empresariales (UAM) entre el 2001 y 2011 y profesor colaborador en el Master de Archivística de la Universidad Carlos III de Madrid. Fue creador y director, entre 2001-2009 y 2013-2015, de la revista TST. Sus principales líneas de investigación se han centrado en la historia de los transportes desde sus vertientes económica, tecnológica y social. Ha publicado medio centenar de monografías y artículos sobre estos temas. Ver https://sites.google.com/site/miguelmunozrub/ 